\title{
Bi-allelic amplification of ATM gene in blastoid variant of mantle cell lymphoma: a novel mechanism of inactivation due to chromoanagenesis?
}

\author{
Veronica Ortega' ${ }^{1}$, Christina Mendiola' ${ }^{1}$ Juana Rodriguez ${ }^{1}$, William Ehman Jr. ', You-Wen Qian²
} and Gopalrao Velagaleti ${ }^{*}$ (1)

\begin{abstract}
Background: Mantle cell lymphoma (MCL) is derived from naïve CD5+ B-cells with the cytogenetic hallmark translocation 11;14. The presence of additional abnormalities is associated with blastoid variants in $\mathrm{MCL}(\mathrm{BMCL})$ and confers a poor prognosis. Many of these tumors also show deletion or loss of heterozygosity $(\mathrm{LOH})$ of the ATM gene and biallelic ATM inactivation show significantly higher chromosomal imbalances.

Case presentation: Here we report a 52 year-old male who presented to the clinic with worsening dyspnea, fever, chills, diffuse lymphadenopathy, splenomegaly and leukocytosis with blastoid cells circulating in blood. The bone marrow aspirate showed about 40\% abnormal blast-looking cells and biopsy revealed a remarkable lymphoid infiltrate. The patient was diagnosed with blastoid variant mantle cell lymphoma (BMCL). Chromosome analysis on bone marrow showed a complex karyotype. FISH analysis from B-cell lymphoma panel showed bi-allelic amplification of ATM gene. Other abnormalities were present including CCND1/IGH fusion, confirming the MCL diagnosis, in addition to RB1 and p53 deletion. High resolution SNP-microarray studies showed complex copy number changes, especially on chromosomes 7 and 11, consistent with chromoanagenesis. Microarray studies also showed LOH at the ATM locus indicating the amplification seen on FISH is not biallelic.
\end{abstract}

Conclusion: To the best of our knowledge, ATM gene amplification is not previously reported in BMCL and our case suggests a novel mechanism of ATM inactivation caused by chromoanagenesis resulting in mutant allele specific imbalance with copy number gain.

Keywords: Mantle cell lymphoma (MCL), Blastoid mantle cell lymphoma (BMCL), Loss of heterozygosity ( $(\mathrm{OH})$ ), Single nucleotide polymorphism (SNP), Mutant allele specific imbalance (MASI), Copy number gain (CNG), Fluorescence in situ hybridization (FISH)

*Correspondence: velagaleti@uthscsa.edu

1 Department of Pathology and Laboratory Medicine, UT Health San Antonio, San Antonio, TX, USA

Full list of author information is available at the end of the article

\section{Background}

The hallmark of mantle cell lymphoma is the $t(11 ; 14)$ resulting in CCND1/IGH fusion leading to overexpression of CCND1 [1]. Alterations of genes involved in cell cycle regulation, DNA damage response mechanisms and activation of cell survival pathways are closely linked to the aggressive and clinical behavior of MCL $[2,3]$. The

(c) The Author(s) 2021. This article is licensed under a Creative Commons Attribution 4.0 International License, which permits use, sharing, adaptation, distribution and reproduction in any medium or format, as long as you give appropriate credit to the original author(s) and the source, provide a link to the Creative Commons licence, and indicate if changes were made. The images or other third party material in this article are included in the article's Creative Commons licence, unless indicated otherwise in a credit line to the material. If material is not included in the article's Creative Commons licence and your intended use is not permitted by statutory regulation or exceeds the permitted use, you will need to obtain permission directly from the copyright holder. To view a copy of this licence, visit http://creativeco mmons.org/licenses/by/4.0/. The Creative Commons Public Domain Dedication waiver (http://creativecommons.org/publicdomain/ zero/1.0/) applies to the data made available in this article, unless otherwise stated in a credit line to the data. 
blastoid variant of MCL usually presents with more complex chromosome abnormalities in addition to the classic $\mathrm{t}(11 ; 14)$ and patients with BMCL have poor prognosis [4]. The ATM (ataxia telangiectasia mutated) gene, also on chromosome 11q22q23 is known to play a significant role in $\mathrm{MCL}$ and frequent $A T M$ gene inactivation has been confirmed in MCL [5]. A high proportion of MCL tumors show deletion or loss of heterozygosity (LOH) spanning the 11q22q23 region $[5,6]$. Studies have shown that MCL tumors with inactivation of both ATM alleles (biallelic) have a significantly increased number of chromosome abnormalities compared to MCL tumors with wild type ATM alleles [5]. It is hypothesized that loss of $A T M$ alleles increases chromosomal instability in these tumors [5]. The loss of ATM function may lead to tumorigenesis mostly through erroneous repair and generation of specific translocations in MCL [5]. In this context, we present an unusual case of ATM amplification which, based on FISH analysis, appears to be biallelic in nature. Since amplification usually results in over expression and not loss of expression, we undertook additional studies to explain this very unusual case of BMCL.

\section{Materials and methods Case presentation}

A 52-year-old male with past medical history of pulmonary embolism, deep vein thrombosis (DVT) of left lower extremity, hepatitis $\mathrm{C}$ virus, intra venous drug abuse, presented to an outside hospital for worsening dyspnea, fever and chills, diffuse lymphadenopathy, splenomegaly and leukocytosis with blast appearing cells on smear review. Imaging studies with CT (computerize tomography) of thorax, abdomen, pelvis and scrotum showed no pulmonary embolism but DVTs were identified for which prophylactic Enoxaparin was given. He was noted to have bilateral pulmonary consolidations being worse on left, bilateral pleural effusions, massive splenomegaly and extensive retroperitoneal lymphadenopathies. Per CBC (complete blood count), there was markedly elevated WBC (white blood cell count), with blast appearing cells on smear review. Upon transfer to our clinic, patient was awake and alert, complained of dyspnea at rest, nonproductive cough, left upper quadrant abdominal pain, bilateral chest pain radiating to back, fever and chills.

CT scan demonstrated extensive retroperitoneal, pelvic and inguinal lymphadenopathies with massive splenomegaly. There was large area of decreased enchancement of the spleen, involving approximately $25 \%$ of the spleen, most likely splenic infarction. $\mathrm{CBC}$ at the admission showed a WBC $68.02 \times 10^{3} / \mathrm{ul}$, RBC $3.76 \times 10^{6} / \mathrm{ul}$, Hgb $10.2 \mathrm{~g} / \mathrm{dl}$, Hct 31.0\%, MCV 82.4 fl, MCH $27.1 \mathrm{pg}$, Platelets $96 \times 10^{3} /$ ul. Differential count showed 25\% Segs; 3\% Bands; 8\% Lymphocytes; 9\% Monocytes; 1\% Eosinophils;
0\% Basophils; 2\% Metamyelocytes; 1\% Myelocytes; 0\% Promyelocytes; $51 \%$ Blasts / blast appearing cells.

The blood smear showed leukocytosis due to the presence of blast appearing cells. These cells appeared medium to large in size with high N/C ratio, open nuclear chromatin pattern and distinctive nucleoli. Neutrophils were slightly left-shifted. Polymorphonuclear leukocytes (PMN) did not show dysplastic changes. Normocytic anemia and thrombocytopenia was also noted.

Bone marrow aspirate showed about $40 \%$ abnormal blast appearing cells with similar morphology as those in the blood. Bone marrow biopsy revealed remarkable lymphoid infiltrate in interstitial pattern and large lymphoid aggregates, contributing to about $40 \%$ of entire cellularity. The infiltrate was composed of mostly immature appearing cells with high N/C ratio and open chromatin. The abnormal cells were immunoreactive to CD20, PAX-5 and Cyclin D1, with a few scattered CD3 T-cells.

\section{Flow cytometry}

Flow cytometry was performed on an 8-color BD FACSCanto II flow cytometer (BD Biosciences, San Jose, CA). Standard operating procedures (SOP) of flow cytometry immunophenotyping for lymphoma and leukemia was followed. Dotplot and histogram was created after data collection. CD45 vs side scatter was used to gate the lymphoid population. CD marker expressions of the abnormal lymphoid population was analyzed on multiple bivariant plots. Flow cytometry from the bone marrow aspirate detected a population (about $50 \%$ of total events) of lambda monoclonal B-cell population expressing CD19, CD22, and FMC-7 with coexpression of CD5, but negative for CD10, CD20, CD43, CD34 and CD38.

Based on these results, the patient was diagnosed with BMCL pending confirmation of chromosome and FISH analyses.

\section{Chromosome analysis}

Cytogenetic analysis was carried out on bone marrow aspirate. Culture initiation, maintenance and harvest were performed using standard methods. Chromosomes were G-banded and then analyzed using a Cytovision image analysis system (Applied Imaging, Santa Clara, CA).

\section{Fluorescence in situ hybridization (FISH)}

FISH was performed on the cultured biopsy specimen using a directly labeled dual color, dual fusion translocation probe CCND1/IGH (IGH labeled in spectrum green and $C C N D 1$ in spectrum orange), ATM deletion probe (ATM labeled in spectrum orange and D11Z1 labeled in spectrum green), $R B 1$ deletion probe ( $R B 1$ labeled in spectrum orange and CTB-163C9 probe in spectrum 
green), $I G H / B C L 2$ dual color, dual fusion probe (IGH labeled in spectrum green and $B C L 2$ in spectrum orange) and TP53 deletion probe (TP53 in spectrum orange and D17Z1 in spectrum green) (Cytocell, Windsor, CT). The probes were hybridized to interphase nuclei and metaphase chromosomes using standard procedures, followed by counterstaining with 4,6-diamidino-2-phenylindole, then analyzed using a Cytovision image analysis system (Applied Imaging, Santa Clara, CA). For interphase analysis, a minimum of 100 nuclei were scored, and for metaphase analysis, a minimum of 10 metaphases were scored.

\section{Single nucleotide polymorphism (SNP) oligonucleotide microarray}

Given the complex nature of the abnormalities observed, chromosome microarray studies were carried out using Affymetrix CytoScan HD microarray. The Affymetrix CytoScan ${ }^{\circledR}$ HD Assay utilizes a high density combined CGH and SNP array platform, which assesses approximately 2,696,550 markers, including approximately 750,000 SNP markers. Each oligonucleotide is approximately 25 base pairs long. Intragenic probe spacing is approximately 1 probe every 880 base pairs and intergenic probe spacing is approximately 1 probe every 1700 base pairs. To perform the assay, gDNA is digested with the Nsp1 restriction enzyme and digested DNA is then ligated to Nsp1 adapters. The ligation product is then amplified via polymerase chain reaction (PCR) to produce amplicons in the $200-1100 \mathrm{bp}$ range. The amplicons are then purified and digested with DNAse I to produce $25-125 \mathrm{bp}$ fragments. The fragments are end-labeled with a modified biotinylated base and the sample is hybridized to the array. The array is washed and stained with a streptavidin-coupled dye and a biotinylated anti-streptavidin antibody. The array is scanned with the GeneChip Scanner and the signal intensity for each marker is assessed. Using the Chromosome Analysis Suite (ChAs 3.0) software, the signal for the sample is then compared to a reference set, which is based on the average of over 400 samples. Differences in signal between the sample and reference are expressed as a log2 ratio and represents relative intensity for each marker. A discrete copy number value is determined from the relative intensity data and is displayed. Genotype information for the SNP markers is visualized with the Allele Track [7].

\section{Results}

Chromosome analysis on bone marrow showed a complex karyotype with multiple numerical and structural abnormalities including deletion of $1 \mathrm{p}$, loss of 7 and 9, rearrangements of chromosome 11, loss of chromosome 13 and several markers. The karyotype was interpreted as $43 \sim 44, \mathrm{X},-\mathrm{Y}$, add $(1)(\mathrm{p} 36.3)$, add (4)(q35),7,-9, add (9)(q34), + 11, add(11)(q23), del(11)(q13),-13,-13,14,-18,-22, + mar1, + mar2, +1 4mar[cp6]/46,XY[14] [8] (Fig. 1a).

The results of interphase FISH analysis showed the characteristic CCND1/IGH fusion (Fig. 1b), distal 13q deletion (Fig. 1c), 3 copies of both $I G H$ and BCL2 gene regions (Fig. 1d) and TP53 gene deletion (Fig. 1e). In addition, the $A T M$ probe showed an unexpected pattern of biallelic amplification (Fig. 1f).

Since the biallelic amplification of ATM gene has not been reported in BMCL, we performed additional highresolution SNP-microarray (Affymetrix CytoScan) studies on the bone marrow aspirate to further characterize this finding. Microarray study demonstrated complex copy number variations consistent with abnormalities observed on routine chromosome analysis (Table 1). The pattern of complex multiple gains and losses, especially on chromosomes 7 (Fig. 2) and 11 (Table 1), is consistent with recently described phenomenon, chromoanagenesis [9]. Analysis of the chromosome 11q22q23 region, where the $A T M$ gene is located, showed focal copy number gain consistent with the ATM amplification seen on FISH studies (Fig. 3a). However, SNP analysis of this region showed $\mathrm{LOH}$ for the entire region including the $A T M$ locus (Fig. 3b).

\section{Discussion and conclusions}

To the best of our knowledge, we report the first case of what appeared to be a biallelic amplification of ATM gene in a patient with BMCL, which upon further studies with high-resolution SNP microarray is shown to be monoallelic with absence/loss of heterozygosity. Our case presents a novel mechanism of tumorigenesis in which the tumor cells acquire focal amplification of mutant $A T M$ gene with loss of wild-type allele resulting in biallelic inactivation resulting in erroneous DNA repair and accumulation of complex chromosomal abnormalities and transformation to BMCL.

Recent studies brought to light two major mechanisms called chromothripsis [10] and chomoanasynthesis [11] to describe the occurrence of tens to hundreds of chromosomal rearrangements occurring within one or a handful of genomic regions. Recognizing that both these mechanisms produce complex, localized rearrangements, Holland and Cleveland [9] proposed the term chromoanagenesis to describe this class of chromosome rearrangements independent of the provoking mechanism. Chromoanagenesis is a catastrophic event resulting in complex chromosomal rearrangements at one or a few chromosomal loci [9]. Such focal inactivation of $R B 1$ gene due to chromothripsis has been 


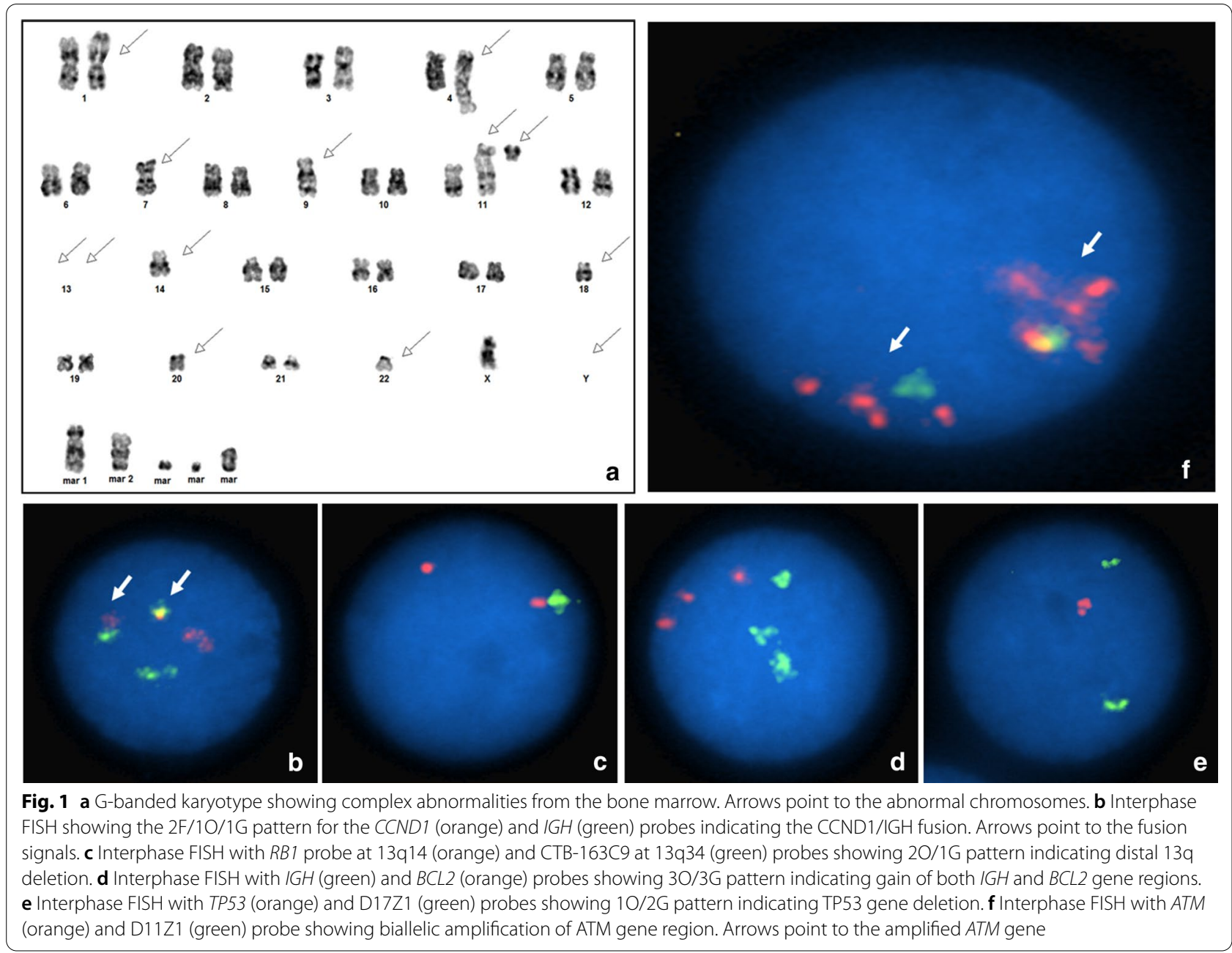

reported in patients with retinoblastoma that lacked the point mutations or indels [12].

Unlike these published cases, the unique feature of our case is that while chromoanagenesis has caused multiple CNV on chromosome 11, the ATM gene locus is not involved in such complex rearrangements. On the other hand, the ATM locus was amplified in our patient, which is contrary to the published literature since amplifications are generally associated with over expression and not lack of expression. Since inactivation or loss of function of ATM locus is reportedly one of the major mechanisms for progression to MCL, we further investigated the apparent $A T M$ amplification detected with FISH testing. The SNP patterns on the microarray suggested that while $A T M$ is present in multiple copies, there is loss of heterozygosity ( $\mathrm{LOH})$ involving this locus. Studies have already showed that LOH involving the ATM gene region results in chromosomal instability and BMCL. As such, the unusual finding by FISH of biallelic amplification of ATM is in fact not biallelic, but is monoallelic with perhaps loss of wild-type allele.

Mutant allele specific imbalance (MASI) is originally coined to describe copy number alterations associated with mutant alleles of oncogenes. Recent advances in genomic analysis tools have further differentiated MASI into those with copy number gains (CNG), with copy neutral alterations (acquired uniparental disomy, UPD), or with LOH due to loss of the wild-type allele [13]. MASI is an established common occurrence in tumors and, in general, is considered an adverse prognostic indicator in tumors. Studies have shown that MASI with loss of wild-type allele can enhance or promote malignant growth.

In light of these observations, we propose that a chromoanagenesis event on chromosome 11 caused MASI with loss of wild-type allele (Fig. 4) to explain the apparent amplification of ATM gene in our case with BMCL. The complex karyotype, especially with loss of $1 \mathrm{p}, 11 \mathrm{q}$, $13 q, 17 p$ and $X$, that are often reported as most frequent 
Table 1 Results of high-resolution SNP Microarray

\begin{tabular}{|c|c|c|c|c|c|c|}
\hline Chr & CNV & Cytoband start & Cytoband end & $\begin{array}{l}\text { Genomic position start-end } \\
\text { GRCh37 }\end{array}$ & Size (Mb) & CN state \\
\hline 3 & Gain & q13.11 & q29 & $104,275,677-197,851,986$ & 93.6 & 3 \\
\hline 3 & GainMosaic & q13.11 & q29 & $104,347,395-197,851,986$ & 93.5 & 3 \\
\hline 4 & LossMosaic & q13.1 & q13.2 & $62,098,409-68,284,650$ & 6.2 & 2 \\
\hline 7 & Gain & p22.3 & p22.1 & $43,360-6,055,929$ & 6.0 & 4 \\
\hline 7 & Gain & q21.13 & q22.1 & $9,1027,069-100,918,485$ & 9.9 & 3 \\
\hline 7 & Loss & p22.1 & p21.3 & $7,263,512-12,522,467$ & 5.3 & 1 \\
\hline 7 & Loss & p21.3 & p14.1 & $13,107,394-37,647,617$ & 24.5 & 1 \\
\hline 7 & Loss & q31.2 & q36.3 & $116,762,426-159,119,707$ & 42.4 & 1 \\
\hline 7 & GainMosaic & p14.2 & p14.1 & $36,647,816-40,257,749$ & 3.6 & 3 \\
\hline 7 & GainMosaic & q21.11 & q22.1 & $85,370,550-103,219,749$ & 17.9 & 3 \\
\hline 7 & LossMosaic & p21.3 & p14.3 & $9,301,862-33,690,301$ & 24.4 & 1 \\
\hline 7 & LossMosaic & q31.31 & q36.3 & $117,402,248-159,119,707$ & 41.7 & 1 \\
\hline 9 & Loss & p24.2 & p13.2 & $2,582,103-38,044,560$ & 35.5 & 1 \\
\hline 9 & LossMosaic & p24.2 & p13.2 & $2,765,255-38,317,590$ & 35.6 & 1 \\
\hline 11 & Gain & p15.5 & p12 & $1,806,954-36,471,669$ & 34.7 & 3 \\
\hline 11 & Gain & q13.4 & $\mathrm{q} 21$ & $74,900,610-9,6287,065$ & 21.4 & 3 \\
\hline 11 & Gain & q21 & $\mathrm{q} 22.2$ & $96,439,368-102,413,943$ & 6.0 & 3 \\
\hline 11 & Gain & q22.2 & q22.3 & $102,414,120-108,729,175$ & 6.3 & 4 \\
\hline 11 & Gain & q22.3 & q23.1 & $109,718,291-111,689,133$ & 2.0 & 4 \\
\hline 11 & Loss & $\mathrm{q} 22.3$ & $\mathrm{q} 22.3$ & $108,729,392-109,715,602$ & 9.9 & 1 \\
\hline 11 & Loss & q23.1 & q25 & $111,731,307-134,788,683$ & 23.1 & 1 \\
\hline 11 & GainMosaic & p15.5 & $\mathrm{p} 12$ & $230,615-36,614,253$ & 36.4 & 3 \\
\hline 11 & LossMosaic & q23.3 & q25 & $114,847,579-134,938,470$ & 20.1 & 1 \\
\hline 13 & Loss & q32.1 & q34 & $95,258,943-114,609,241$ & 19.4 & 1 \\
\hline 13 & LossMosaic & q12.3 & $\mathrm{q} 21.2$ & $31,921,726-62,123,665$ & 30.2 & 2 \\
\hline 13 & LossMosaic & q32.1 & q34 & $96,138,381-115,107,733$ & 19.0 & 1 \\
\hline 14 & Gain & q32.33 & q32.33 & $106,072,250-106,692,891$ & 0.6 & 3 \\
\hline 17 & Loss & p13.3 & p11.2 & $525-21,565,553$ & 21.6 & 1 \\
\hline 17 & LossMosaic & p13.3 & p11.2 & $525-20,007,075$ & 20.0 & 1 \\
\hline 19 & Gain & $\mathrm{q} 13.12$ & q13.43 & $37,805,520-58,813,857$ & 21.0 & 3 \\
\hline 19 & GainMosaic & $\mathrm{q} 13.12$ & q13.43 & $37,516,085-58,956,888$ & 21.4 & 3 \\
\hline$x$ & Loss & p22.33 & p21.3 & $2,693,466-25,047,578$ & 22.4 & 1 \\
\hline$x$ & Loss & p21.3 & q23 & $25,048,192-115,589,080$ & 90.5 & 1 \\
\hline$x$ & Loss & q23 & q24 & $115,592,089-118,552,562$ & 3.0 & 1 \\
\hline$x$ & Loss & $\mathrm{q} 24$ & $\mathrm{q} 28$ & $118,552,991-155,059,506$ & 36.5 & 1 \\
\hline Y & Gain & p11.31 & q11.23 & $2,660,575-28,799,937$ & 26.1 & 1 \\
\hline
\end{tabular}

additional abnormalities in MCL, further strengthens the hypothesis that $A T M$ gene inactivation resulted in erroneous DNA replication and accumulation of complex chromosomal rearrangements.

One of the major limitations of our study is our inability to perform functional studies to determine the loss of expression of ATM gene. Non-availability of fresh patient sample for RNA extraction limited the options for additional functional studies. Another limitation of the study, in terms of limited availability of material in a clinical setting and lack of technical and other resources, does not allow us to investigate other possible hypotheses such as the complex rearrangements on chromosome 11 disrupting the ATM gene and the resulting haploinsufficiency contributing to loss of expression of ATM gene.

In summary, we report a unique case of BMCL with ATM amplification with $\mathrm{LOH}$ and propose that MASI with loss of wild-type allele due to chromoanagenesis resulted in loss of ATM expression leading to tumorigenesis. 


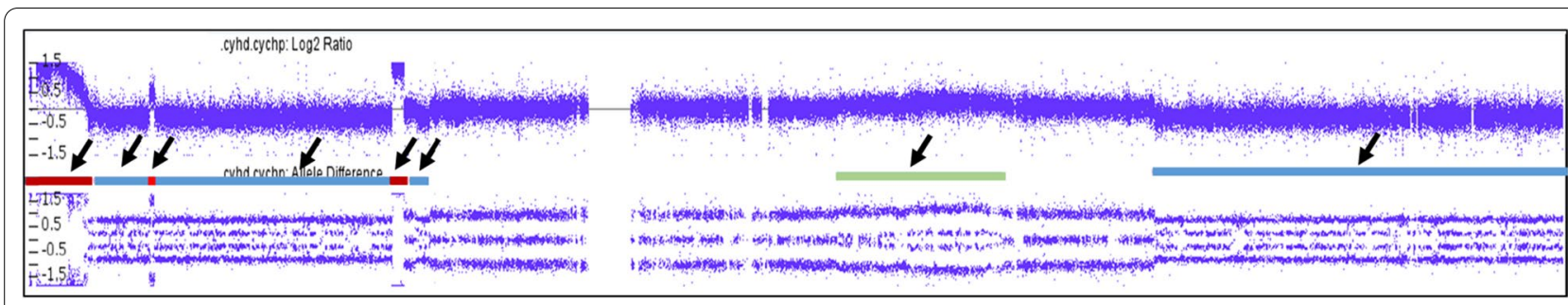

\section{CNV - gain ( $\sim 4$ copies) with LOH \\ CNV - loss \\ CNV - gain ( 3 copies) \\ CNV - gain (2 3 copies)}

Fig. 2 High-resolution SNP microarray showing complex CNV on chromosome 7. Arrows point to various CNV observed

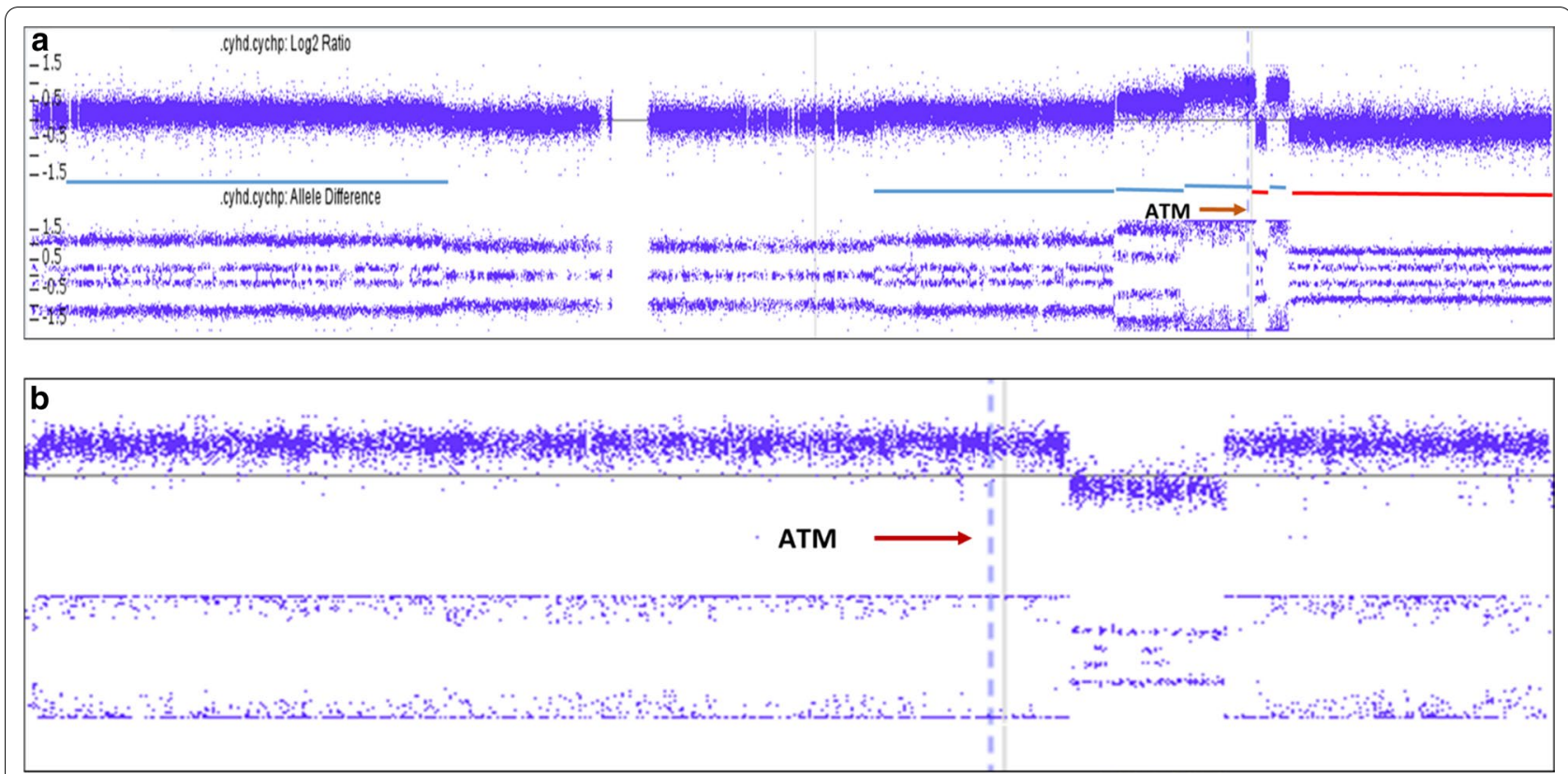

Fig. 3 a High-resolution SNP microarray showing complex CNV on chromosome 11. Arrow points to the ATM locus. b Enlarged figure showing 11 q22q23 region on high resolution SNP microarray showing $\mathrm{LOH}$ at the ATM locus. Arrow points to the ATM locus

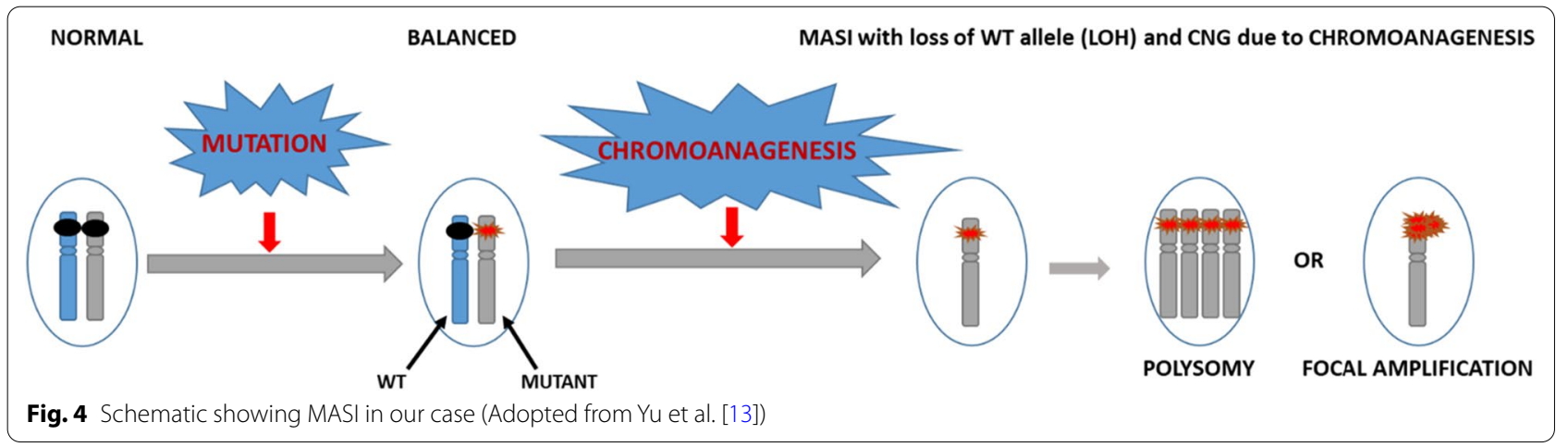




\section{Abbreviations}

MCL: Mantle cell lymphoma; BMCL: Blastoid variant of mantle cell lymphoma; FISH: Fluorescence in situ hybridization; MASI: Mutant allele specific imbalance; SNP: Single nucleotide polymorphisms.

\section{Authors' contributions}

$\mathrm{VO}, \mathrm{CM}, \mathrm{JR}, \mathrm{WE}$, GV performed the studies and writing of the manuscript. YQ provided the clinical data and helped write the manuscript. All authors read and approve the final manuscript.

\section{Funding}

There was no funding available for this study.

\section{Availability of data and materials}

All relevant data and material is included in this publication.

\section{Ethics approval and consent to participate}

Not applicable since this is a case report and no patient identifiers are used.

\section{Consent for publication}

Not applicable.

\section{Competing interests}

The authors declare that they have no competing interests.

\section{Author details}

${ }^{1}$ Department of Pathology and Laboratory Medicine, UT Health San Antonio, San Antonio, TX, USA. ${ }^{2}$ Department of Pathology, University of Texas Medical Branch, Galveston, TX, USA.

Received: 21 October 2020 Accepted: 28 December 2020

Published online: 04 February 2021

\section{References}

1. Swerdlow S, Campo E, Harris N, Jaffe E, Pileri S, Stein H, et al. WHO classification of tumours of haematopoietic and lymphoid tissues. Lyon: IARC; 2008.
2. Jares P, Colomer D, Campo E. Genetic and molecular pathogenesis of mantle cell lymphoma: perspectives for new targeted therapeutics. Nat Rev Cancer. 2007;7:750-62

3. Jares P, Campo E. Advances in the understanding of mantle cell lymphoma. Br J Haematol. 2008;142:149-65.

4. Seok Y, Kim J, Choi JR, Kim YR, Park SJ, Kim SJ, Song J, Lee KA. CD5-negative blastoid variant mantle cell lymphoma with complex CCND1/IGH and MYC aberrations. Ann Lab Med. 2012;32:95-8.

5. Stankovic T, Stewart CS, Byrd P, Fegan C, Moss PAH, Taylor AMR. ATM mutations in sporadic lymphoid tumours. Leuk Lymph. 2002;43:1563-71.

6. Stilgenbauer S, Winkler O, Ou G, Schaffner C, Leupolt E, Bentz M, et al. Molecular characterization of $11 \mathrm{q}$ deletions points to a pathogenic role of the ATM gene in mantle cell lymphoma. Blood. 1999;94:3262-4.

7. Webb BD, Scharf RJ, Spear EA, Edelmann LJ, Stroustrup A. Evaluation of the Affymetrix Cytoscan ${ }^{\circledR}$ Dx assay for developmental delay. Expert Rev Mol Diagn. 2015;15:185-92.

8. McGowan-Jordan J, Simons A, Schmid M. An international system for human cytogenomic nomenclature. Basel: Karger; 2016.

9. Holland AJ, Cleveland DW. Chromoanagenesis and cancer: mechanisms and consequences of localized, complex chromosomal rearrangement. Nat Med. 2012;18:1630-8.

10. Stephens PJ, Greenman CD, Fu B, Yang F, Bignell GR, Mudie LJ, et al. Massive genomic rearrangement acquired in a single catastrophic event during cancer development. Cell. 2011;144(1):27-40.

11. Liu P, Erez A, Sreenath Nagamani SC, Dhar SU, Kolodziejska KE, Dharmadhikari AV, et al. Chromosome catastrophes involve replication mechanisms generating complex genomic rearrangements. Cell. 2011;146(6):889-903.

12. McEvoy J, Nagahawatte P, Finkelstein D, Richards-Yutz J, Valentine M, Ma J, et al. RB1 gene inactivation by chromothripsis in human retinoblastoma. Oncotarget. 2014:5(2):438-50.

13. Yu C-C, Qui W, Juang CS, Mansukhani MM, Halmos B, Su GH. Mutant allele specific imbalance in oncogenes with copy number alterations: occurrence, mechanisms, and potential clinical implications. Cancer Lett. 2017;384:86-93.

\section{Publisher's Note}

Springer Nature remains neutral with regard to jurisdictional claims in published maps and institutional affiliations.
Ready to submit your research? Choose BMC and benefit from:

- fast, convenient online submission

- thorough peer review by experienced researchers in your field

- rapid publication on acceptance

- support for research data, including large and complex data types

- gold Open Access which fosters wider collaboration and increased citations

- maximum visibility for your research: over 100M website views per year

At BMC, research is always in progress.

Learn more biomedcentral.com/submissions 